\title{
A peak shift resulting from a chained reinforcement schedule
}

JEROME FRIEMAN, Kansas State University, Manhattan, Kans. 66502, and DAVID R. THOMAS, University of Colorado, Boulder, Colo. 80302

Ten pigeons were given VI 2-min single-stimulus training and then were switched to a chain VI I-min VI I-min schedule. For half of the Ss, the original training stimulus became the stimulus closest to primary reinforcement $\left(S_{1}\right)$ and a new stimulus became the stimulus farthest from primary reinforcement $\left(S_{2}\right)$. For the other $S s$, the training stimulus became $S_{2}$ and the new stimulus became $S_{1}$. After $5 \% / 2 h$ of training on the chained schedule, a generalization test in extinction revealed peak shifts away from $S_{2}$ beyond $S_{1}$ in both groups.

In operant successive discrimination training, Ss are taught that responses in the presence of one stimulus (the positive) are rewarded either with greater frequency (Guttman, 1959; Hanson, 1959) or with a greater magnitude (Mariner \& Thomas, 1969) than are responses in the presence of another stimulus (the negative), or that responding must be maintained at a lower rate in the presence of the negative
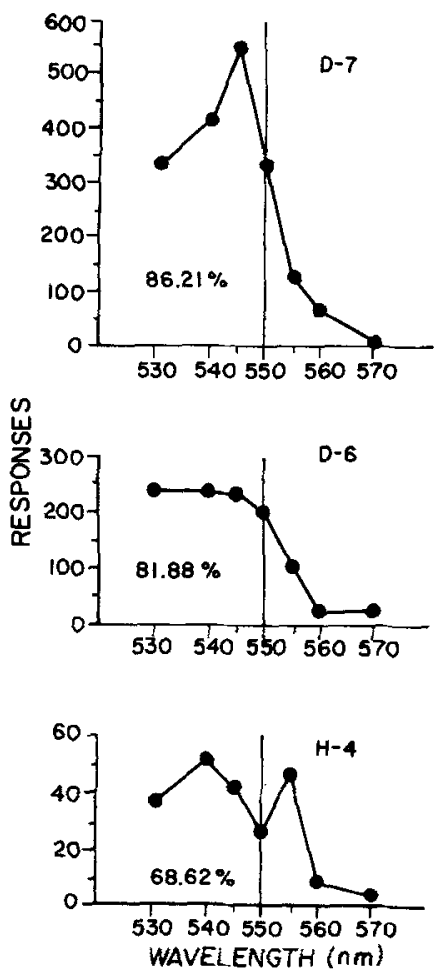

stimulus in order for reinforcement to occur (Terrace, 1966). When the two stimuli are closely spaced on the same physical dimension and the response rate in the presence of the negative stimulus is reduced relative to the response rate in the presence of the positive stimulus, the peak of the postdiscrimination generalization gradient is displaced from the positive stimulus so as to be farther removed from the negative. Terrace (1966) has suggested that, under these conditions, the negative stimulus is aversive relative to the positive stimulus, and that the "peak shift" in the postdiscrimination gradient is an indication of the aversiveness of the negative stimulus.

A standard procedure for identifying an aversive stimulus is to train a response that will lead to avoidance or escape from that stimulus. J. R. Thomas (1966) found that pigeons will learn a new response (pecking a second key) to avoid return to the component farthest from primary reinforcement in a chained schedule of reinforcement. Unfortuantely, it is not possible to determine in Thomas's experiment whether the $S$ is avoiding the component farthest from primary reinforcement or is simply prolonging the duration of the component nearest primary reinforcement. If Terrace's suggestion that
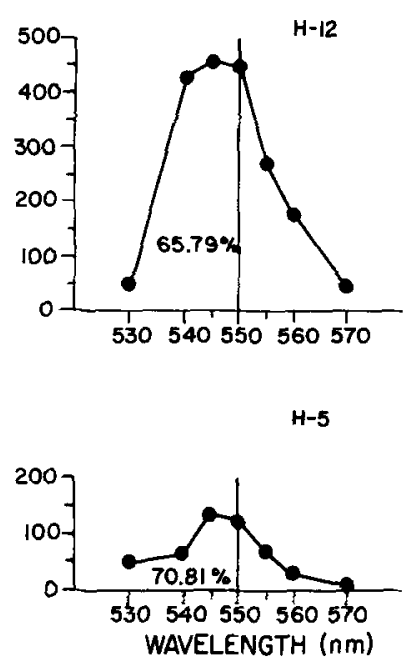

GROUP I

$\mathrm{TS}=570 \mathrm{~nm}$

$S_{1}=550 \mathrm{~nm}$
$S_{2}=570 \mathrm{~nm}$ a stimulus associated with a reduced rate of responding is aversive is correct, and Thomas's Ss were indeed avoiding the component farthest from food, then one would also expect that a peak shift would occur in a chained schedule away from the stimulus associated with the component farthest from food. This hypothesis was tested in the present experiment.

\section{SUBJECTS}

The Ss were 10 experimentally naive homing pigeons, maintained at approximately $70 \%$ of their free-feeding weights.

\section{APPARATUS}

All training and testing took place in a Skinner-type automatic key-pecking apparatus described by Thomas \& Lopez (1962). The key was illuminated by a Bausch and Lomb monochromator, Model 33-86-02, equipped with a tungsten light source. There was no houselight.

\section{PROCEDURE}

On Day I, all Ss were magazine trained, key-peck trained, and given 50 continuous reinforcements of 4-sec access to the grain hopper. Thirty more continuous reinforcements were given on Day 2, and on Day 3 Ss were given 30 more reinforcements on an FR-5 schedule. This was done to facilitate the subsequent transition to a VI 2-min schedule. For the next 10 days, all $S s$ were placed on a VI 2-min schedule for $1 \mathrm{~h}$ each day, For half the Ss, all training to this point was with a 550-nm light on the key, and for the other half, the key was illuminated by a 570-nm light.

After completion of VI training, each of these groups was placed on a chain VI 1-min VI 1-min schedule with $550 \mathrm{~nm}$ associated with the component nearest the primary reinforcement $\left(S_{1}\right)$ and $570 \mathrm{~nm}$ associated with the component farthest from primary reinforcement $\left(S_{2}\right)$. Between components of the chain, there was a 4-sec blackout during which the stimulus on the key was changed. To describe the procedure more explicitly, $S_{2}$ came on and remained on for a variable period of time averaging $1 \mathrm{~min}$. At the end of this interval, the first peck terminated $S_{2}$ and initiated a 4-sec blackout, at the end of which $S_{1}$ appeared and remained on for a variable period of time, again averaging $1 \mathrm{~min}$. The first peck at the end of this interval terminated $S_{1}$ and produced a 4 -sec access to the food hopper, during which another blackout occurred, and then the cycle was repeated.

Fig. 1. Generalization gradients for Ss trained on $570 \mathrm{~nm}$, which was subsequently made $S_{2}$. 


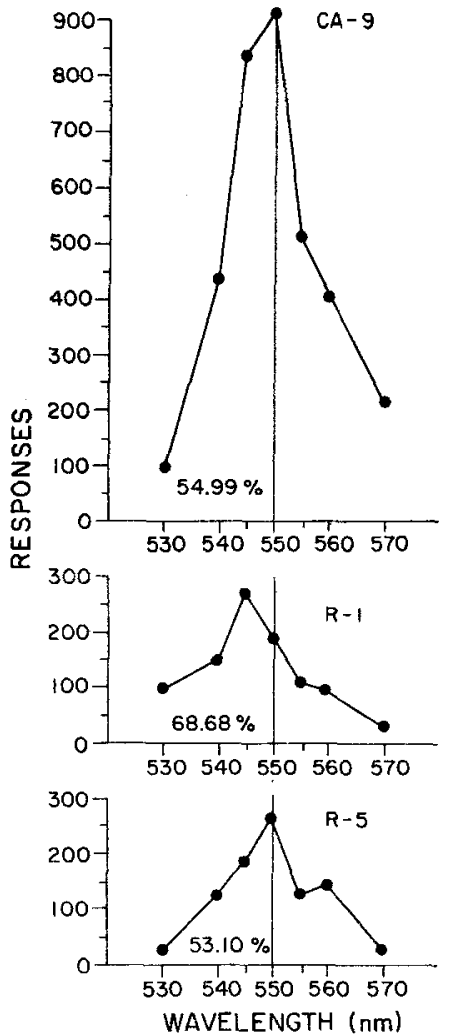

All Ss were given 5 1-h daily sessions on the chained schedule. On the six th day of chained performance, Ss were given a $1 / 2-h$ (reinforced) warm-up with the chain and then a generalization test in extinction with seven monochromatic stimuli (530, $540,545,550,555,560$, and $570 \mathrm{~nm}$ ) presented in each of six random series. Each stimulus was presented for $60 \mathrm{sec}$, with a 4-sec blackout between presentations, during which responses were recorded and the test stimuli changed.

\section{RESULTS AND DISCUSSION}

All Ss exhibited high response rates in both components of the chain at the beginning of chain training; however, by the end of the third day of training on the chain, all Ss responded at a very low rate in the presence of $S_{2}$, while continuing to respond at a high rate to $S_{1}$. Over the course of the 6 days of training on the chain, the rate of responding in the presence of $S_{2}$ tended to stabilize, and this maintenance of responding in the presence of $S_{2}$ indicates that the training schedule was functionally a chain, despite the interpolation of the 4-sec blackout between the presentation of the two monochromatic stimuli. In other

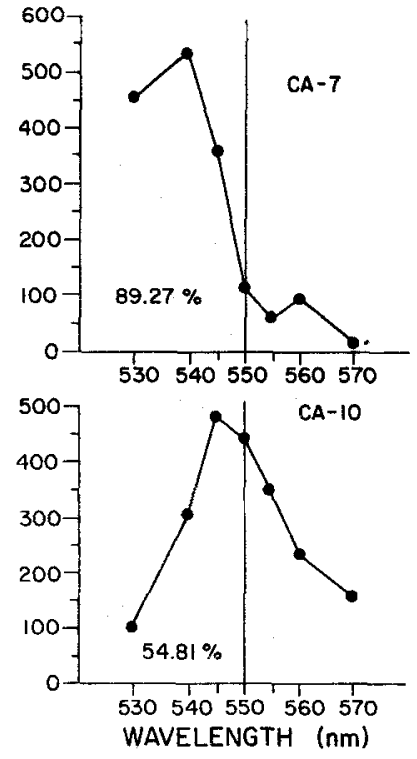

GROUP 2

$\mathrm{TS}=550 \mathrm{~nm}$

$S_{\mid}=550 \mathrm{~nm}$

$S_{2}=570 \mathrm{~nm}$
Fig. 2. Generalization gradients for Ss trained on $550 \mathrm{~nm}$, which was subsequently made $S_{1}$.

enhanced responding to longer wavelengths. Thus, it may be concluded that in the present study both an "area shift" and a "peak shift" away from the $570-\mathrm{nm} \mathrm{S}_{2}$ took place.

The finding of a shift in the gradients in the direction opposite $S_{2}$ in both training conditions in this experiment relates J. R. Thomas's (1966) finding that pigeons will learn a new response to avoid return to the initial component of a chained schedule to Terrace's (1966) contention that the stimulus associated with a reduced rate of responding is aversive. Taken together, these two experiments suggest that Thomas's Ss were indeed avoiding the initial component of the chain and that the stimulus associated with that component is aversive relative to a stimulus closer to primary reward. experiments involving the same two training stimuli (cf., e.g., Hanson, 1959) and a multiple (VI-extinction) schedule, responding to the extinguished stimulus falls to zero with less training than was used here.

Figures 1 and 2 present the individual gradients for each $\mathrm{S}$ in Groups 1 and 2, respectively. In Group 1, for which the training stimulus was made $S_{2}$, all five birds showed peak shifts. In Group 2, for which the training stimulus was made $S_{1}$, three peak shifts were obtained.

As Terrace (1966) has pointed out, the peak shift is not as sensitive a measure of the effects of discrimination training as is the degree of asymmetry in the postdiscrimination generalization gradient. Therefore, an asymmetry score was obtained for each $S$ by computing the percentage of responding to stimuli other than $S_{1}$, which occurred to stimuli on the side of $S_{1}$ opposite $S_{2}$. These scores, also presented in the figures, are above $50 \%$ for each $S$ in the experiment. The bulk of the literature in which single-stimulus training has been given with the $550-\mathrm{nm}$ stimulus (starting with Guttman \& Kalish, 1956) shows gradients that peak at the CS value and are asymmetrical in the direction of

\section{REFERENCES}

GUTTMAN, N. Generalization gradients around stimuli associated with different reinforcement schedules. Journal of Experimental Psychology, 1959, 58, 335-340.

GUTTMAN, N., \& KALISH, H. I. Discriminability and stimulus generalization. Journal of Experimental Psychology, 1956 $51,79-88$.

HANSON, H. M. Effects of discrimination training on stimulus generalization. Journal of Experimental Psychology, 1959, 58, 321-334.

MARINER, R. W., \& THOMAS, D. R. Reinforcement duration and the peak shift in postdiscrimination gradients. Journal of the Experimental Analysis of Behavior, 1969, 12, 759-766.

TERRACE, H. S. Stimulus control. In W. K. Honig (Ed.), Operant behavior: Areas of research and applications. New York: Appleton-Century-Crofts, 1966. Pp. 271-344.

THOMAS, D. R., \& LOPEZ, L. J. The effects of delayed testing on generalization slope. Journal of Comparative \& Physiological Psychology, 1962, 55, 541-544.

THOMAS, J. R. Avoidance of a return to the first component of a chain from the terminal component. Journal of the Experimental Analysis of Behavior, 1966, 9, 435-441. NOTE

1. This research was performed at Kent State University and was supported by N.I.H. Research Grants HD-00903-06 and HD-03486-01 under the direction of David R. Thomas. Reprints may be obtained from Jerome Frieman, Department of Psychology, Kansas State University, Manhattan, Kans. 66502. 